\title{
The Spectral Signature of Recent Climate Change
}

\author{
H. E. Brindley ${ }^{1}$ R. J. Bantges ${ }^{1}$
}

Published online: 1 July 2016

(C) The Author(s) 2016. This article is published with open access at Springerlink.com

\begin{abstract}
Spectrally resolved measurements of the Earth's reflected shortwave (RSW) and outgoing longwave radiation (OLR) at the top of the atmosphere intrinsically contain the imprints of a multitude of climate relevant parameters. Here, we review the progress made in directly using such observations to diagnose and attribute change within the Earth system over the past four decades. We show how changes associated with perturbations such as increasing greenhouse gases are expected to be manifested across the spectrum and illustrate the enhanced discriminatory power that spectral resolution provides over broadband radiation measurements. Advances in formal detection and attribution techniques and in the design of climate model evaluation exercises employing spectrally resolved data are highlighted. We illustrate how spectral observations have been used to provide insight into key climate feedback processes and quantify multi-year variability but also indicate potential barriers to further progress. Suggestions for future research priorities in this area are provided.
\end{abstract}

Keywords Reflected shortwave and outgoing longwave radiation $\cdot$ Radiative forcing and feedback signatures $\cdot$ Natural variability $\cdot$ Detection and attribution of climate change

This article is part of the Topical Collection on Global Energy Budgets

H. E. Brindley

h.brindley@imperial.ac.uk

1 Space and Atmospheric Physics Group, and NERC National Centre for Earth Observation, Imperial College London, London, UK

\section{Introduction}

The balance between net incoming solar radiation and outgoing terrestrial radiation at the top of the Earth's atmosphere (TOA) fundamentally drives our climate system. Perturbations to this balance, either as a result of natural variability or anthropogenic activity, ultimately result in either a heating or cooling of the Earth system such that measurements of the Earth's radiation budget (ERB) at the TOA are essential in order to understand how our climate is evolving with time.

Broadband, spectrally integrated measurements of the solar radiation reflected by the Earth (reflected shortwave, RSW) and outgoing longwave radiation (OLR) emitted by the Earth have been made by a variety of satellite sensors for over four decades (Fig. 1a and Table 1). Despite the limited lifetimes of individual satellite missions, changes in measurement techniques and uncertainties in instrument calibration resulting in some controversy regarding the absolute level of the various components at any given time $[9,10]$, these observations have had a major impact on our understanding of, and ability to model, our climate system [11-14]. However, there is a caveat: broadband measurements effectively integrate all the energy across the shortwave or longwave spectrum which may mask signatures associated with particular climate processes due to compensating effects [15].

In contrast, spectrally resolved measurements of the outgoing radiation can be used to identify and monitor the effects of many different processes $[16,17]$. This is not surprising since satellite observations of the reflected and emitted radiation in different wavelength bands across the RSW and OLR spectrum are routinely used to retrieve many geophysical parameters from surface temperature to cloud optical properties. However, whilst the potential for the simultaneous detection and attribution of climate change using direct observations of the spectrally resolved OLR has been recognised for some 
Fig. 1 a Examples of some of the key satellite observations of RSW and OLR over the past five decades. b As (a) for spectral RSW and OLR. Note that narrowband, spectrally non-continuous measurements are not included. In each case, the name of the satellite on which the instrument flew or is currently flying is provided in brackets. Arrows indicate the instrument is still operational a

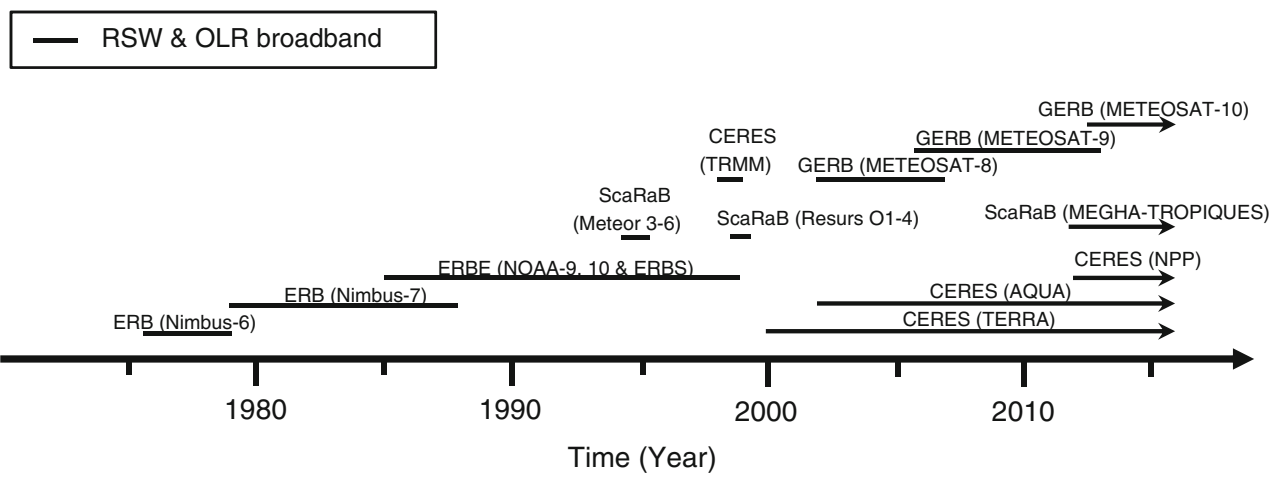

b

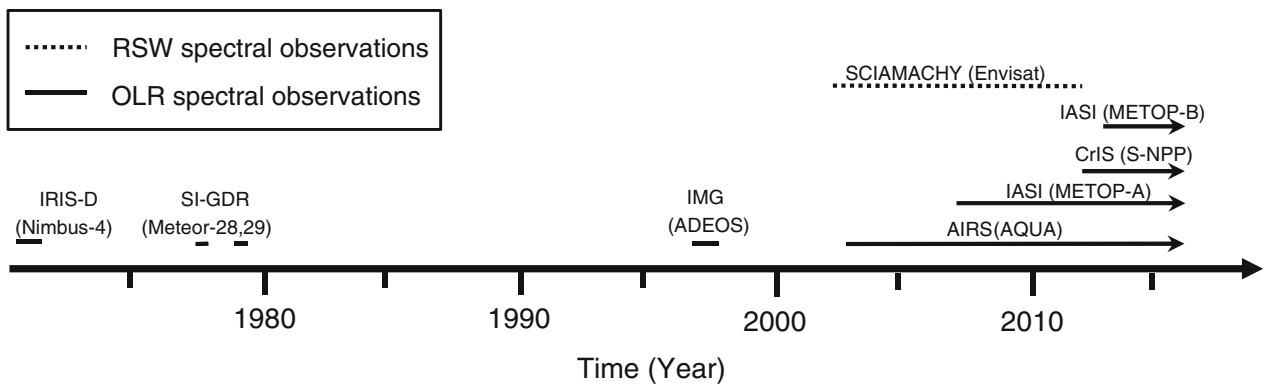

time [18], it is only relatively recently, with the advent of multi-year hyperspectral measurements (Fig. $1 \mathrm{~b}$ and Table 2) and advanced computing capabilities, that significant progress has been made in illustrating the power of these observations. Recently, researchers have also begun to utilise hyperspectral RSW measurements in detection and attribution studies and exciting progress has been made in combining the information contained within the OLR and RSW regimes [27•]. This review paper summarises these new advances, setting them in the context of previous work and considers future developments in the area. Whilst we note the contribution that the long-term availability of stable hyperspectral measurements has undoubtedly made and will continue to make to our ability to derive key climate variables such as temperature, carbon dioxide and water vapour [28-30], with recent studies demonstrating how well such retrievals map to the observed radiance trends [31], our focus in this article is on the direct use of the observed radiances in climate change research.

\section{Early Work: the 1980s}

Concern in the late 1970s regarding the potential impact of increases in atmospheric $\mathrm{CO}_{2}$ on the Earth's climate saw a number of scientific papers devoted to detecting a clear, $\mathrm{CO}_{2}$ induced signal in variables including surface temperature [32, 33], ice cover [34] and sea level rise [35]. The difficulty in attributing the response of the chosen variable to a specific cause given the natural variability of, and confounding factors within, the climate system was a common theme in these studies. In their work, Madden and Ramanathan mooted the possibility of using spectrally resolved satellite observations of the ERB to provide this attribution, suggesting that whilst increasing $\mathrm{CO}_{2}$ should reduce the outgoing energy within its absorption bands, the expected associated surface heating should enhance emission within more transparent regions of the spectrum. Should this surface heating trigger feedbacks such as changes in cloud amount, the RSW energy would also change.

Developing this suggestion, Kiehl simulated changes in clear-sky spectrally resolved OLR in the strong $15-\mu \mathrm{m}$ $\left(667 \mathrm{~cm}^{-1}\right)$ band for a doubling of atmospheric $\mathrm{CO}_{2}[36]$. His work investigated the impact of both $\mathrm{CO}_{2}$ increases alone and when considered in concert with the associated tropospheric and stratospheric temperature response. In isolation, $\mathrm{CO}_{2}$ increases result in enhanced absorption across the band, shifting the emitting level seen from space to higher in the atmosphere. At band centre, this shift is to higher levels in the stratosphere where temperature increases with height, increasing the emission to space. Conversely, in the band wings, the shift occurs within the troposphere where temperature decreases with height, reducing the outgoing radiation. The result is a cooling of the stratosphere and warming of the troposphere and surface. Hence, when the temperature response to a $\mathrm{CO}_{2}$ increase is included, the $\mathrm{CO}_{2}$-only changes 
Table 1 Characteristics of broadband instruments highlighted in Fig. 1a

\begin{tabular}{|c|c|c|c|}
\hline Instrument name & Spectral range & $\begin{array}{l}\text { Spatial resolution } \\
\text { (at nadir) }(\mathrm{km})\end{array}$ & $\begin{array}{l}\text { Temporal coverage (launch date to end of } \\
\text { instrument operation) }\end{array}$ \\
\hline Earth Radiation Budget (ERB) $[1,2]$ & $\begin{array}{l}\text { Broadband OLR and RSW } \\
\text { SW and IR channels }\end{array}$ & $\begin{array}{l}500^{\mathrm{a}} \\
150^{\mathrm{a}}\end{array}$ & $\begin{array}{l}\text { June 1975-October } 1978 \text { (Nimbus-6) } \\
\text { October 1978-October } 1987 \text { (Nimbus-7) }\end{array}$ \\
\hline $\begin{array}{l}\text { Earth Radiation Budget Experiment } \\
\text { (ERBE) [3] }\end{array}$ & $\begin{array}{l}\text { Broadband } \\
\text { OLR and RSW }\end{array}$ & $40^{\mathrm{a}}$ & 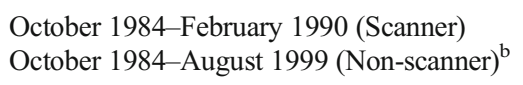 \\
\hline $\begin{array}{l}\text { Clouds and the Earth's Radiant Energy } \\
\text { System (CERES) [4] }\end{array}$ & $\begin{array}{l}\text { Broadband } \\
\text { OLR and RSW } \\
\text { IR window channel }\end{array}$ & $\begin{array}{l}10 \\
20\end{array}$ & $\begin{array}{l}\text { November 1997-September } 1998 \text { (TRMM) } \\
\text { December 1999-present (Terra) } \\
\text { April 2002-present (Aqua) } \\
\text { October 2011-present (NPP) }\end{array}$ \\
\hline $\begin{array}{l}\text { Geostationary Earth Radiation Budget } \\
\text { (GERB) [5] }\end{array}$ & $\begin{array}{l}\text { Broadband } \\
\text { OLR and RSW }\end{array}$ & 50 & $\begin{array}{l}\text { August 2002-April } 2007 \text { (Meteosat-8) } \\
\text { December 2005-January } 2013 \text { (Meteosat-9) } \\
\text { July 2012-present (Meteosat-10) }\end{array}$ \\
\hline $\begin{array}{l}\text { Scanner for Radiation Budget } \\
\text { (ScaRaB) [6-8] }\end{array}$ & $\begin{array}{l}\text { Broadband } \\
\text { OLR and RSW } \\
\text { Visible and IR window } \\
\text { channels }\end{array}$ & $\begin{array}{l}60 \\
41 \\
40\end{array}$ & $\begin{array}{l}\text { January 1994-March } 1995 \text { (Meteor) } \\
\text { July 1998-March } 1999 \text { (Resurs 01-4) } \\
\text { October 2011-present (Megha-Tropiques) }^{\text {e }}\end{array}$ \\
\hline
\end{tabular}

Apart from the exceptions noted below, all instruments have global coverage

${ }^{a}$ The quoted spatial resolution corresponds to the analysed ERB data from the scanning, narrow field of view channels on the relevant satellites, coarser resolution is provided by the wide field of view non-scanner measurements

${ }^{\mathrm{b}}$ The non-scanner instrument on the ERBS satellite viewed the region $60-60^{\circ} \mathrm{N} / \mathrm{S}$

${ }^{\mathrm{c}}$ CERES on TRMM viewed the region $40-40^{\circ} \mathrm{N} / \mathrm{S}$

${ }^{\mathrm{d}}$ GERB fluxes are produced for the region $60-60^{\circ} \mathrm{N} / \mathrm{S}$ and E/W. Note that although GERB-3 on Meteosat-10 is the operational instrument, both GERB-1 and GERB-2 are still functioning

${ }^{\mathrm{e}} \mathrm{ScaRaB}$ on Megha-Tropiques views the region $20-20^{\circ} \mathrm{N} / \mathrm{S}$

in OLR are mediated and, in the centre of the band, change sign. Charlock extended Kiehl's study to a wider spectral range, including the $4.3-\mu \mathrm{m}\left(2325 \mathrm{~cm}^{-1}\right) \mathrm{CO}_{2}$ band and incorporating the atmospheric humidity response to the $\mathrm{CO}_{2}$ doubling [37]. His results confirmed Kiehl's findings but also showed that clear-sky emission to space within the atmospheric window $\left(8-12 \mu \mathrm{m} ; \sim 800-1250 \mathrm{~cm}^{-1}\right)$ would be expected to increase. Whilst these early results were obtained using radiative transfer codes and atmospheric realisations that would now be considered far from state-of-the-art, the basic findings remain true (Fig. 2).

\section{A Topic Revisited: 1990s-Early 2000s}

Despite their promise, these theoretical studies did not immediately spark huge interest in the use of spectrally resolved OLR to detect and attribute climate change. Indeed, it was not until the mid-1990s that interest in the topic was revived, principally due to the re-evaluation of observations from the InfraRed Interferometer Spectrometer (IRIS-D) by Goody and co-workers at CalTech. IRIS-D, on the Nimbus-4 meteorological satellite, measured the Earth's outgoing longwave spectrum from April 1970 to January 1971 [19]. Spanning the range $400-1600 \mathrm{~cm}^{-1}(6.25-25 \mu \mathrm{m})$ with a nominal spectral resolution of $2.8 \mathrm{~cm}^{-1}$, observations from the instrument had previously been used to provide insight into the spatiotemporal distribution of variables such as methane and cirrus cloud $[38,39]$. Motivated both by the prospect of long-term hyperspectral measurements from the proposed Atmospheric InfraRed Sounder (AIRS) and the development of mathematical techniques to optimise fingerprints of climate change [40], Goody used the IRIS-D measurements to estimate the 'weather noise' or short-term variability of the Earth's OLR spectrum. Combining these estimates with simulated 'climate forcing' signals due to, for example, a doubling of $\mathrm{CO}_{2}$ or an increase in incoming solar flux, he introduced the concepts of spectral selectivity and sensitivity. The former term relates to the ability to distinguish between forcings, the latter, the time needed for a signal to emerge from background noise [18].

Whilst this study indicated that in certain regions of the spectrum a distinct change signal could be identified and attributed to a particular forcing with reasonable confidence, the authors acknowledged that the work was designed more to stimulate further discussion than give definitive answers regarding the most promising detection strategy. The CalTech group continued to refine their approach whilst championing the use of well-calibrated, accurate, spectrally resolved OLR measurements to test climate model performance [41-43]. 
Table 2 Characteristics of spectrally resolved instruments highlighted in Fig. 1b

\begin{tabular}{|c|c|c|c|c|}
\hline Instrument name & Spectral range & Spectral resolution & $\begin{array}{l}\text { Spatial resolution } \\
\text { (at nadir) }(\mathrm{km})\end{array}$ & $\begin{array}{l}\text { Temporal coverage (launch } \\
\text { date to end of instrument } \\
\text { operation) }\end{array}$ \\
\hline $\begin{array}{l}\text { InfraRed Interferometer Spectrometer } \\
\text { (IRIS-D) [19] }\end{array}$ & $400-1600 \mathrm{~cm}^{-1}$ & $2.8 \mathrm{~cm}^{-1}$ & 100 & April 1970-January 1971 \\
\hline $\begin{array}{l}\text { Spectrometer/Interferometer of the } \\
\text { German Democratic Republic } \\
\text { (SI-GDR) [20] }\end{array}$ & $400-1600 \mathrm{~cm}^{-1}$ & $5.0 \mathrm{~cm}^{-1}$ & 23 & $\begin{array}{l}\text { June 1977-September } 1977 \\
\text { (Meteor-28) } \\
\text { January 1979-June } 1979 \\
\text { (Meteor-29) }\end{array}$ \\
\hline $\begin{array}{l}\text { Interferometric Monitor for } \\
\text { Greenhouse Gases (IMG) [21] }\end{array}$ & $\begin{array}{l}650-3000 \mathrm{~cm}^{-1} \\
\quad(3 \text { contiguous bands })\end{array}$ & $\begin{array}{l}0.1 \text { to } 0.25 \mathrm{~cm}^{-1} \text {, } \\
\text { varying with band }\end{array}$ & 8 & October 1996-June 1997 \\
\hline $\begin{array}{l}\text { Scanning Imaging Absorption } \\
\text { Spectrometer for Atmospheric } \\
\text { Cartography (SCIAMACHY) [22] }\end{array}$ & $\begin{array}{l}240-2380 \mathrm{~nm} \\
\text { ( } 3 \text { non-contiguous } \\
\text { bands) }\end{array}$ & $0.22-1.48 \mathrm{~nm}$ & $30 \times 240$ & March 2002-May 2012 \\
\hline $\begin{array}{l}\text { Atmospheric Infrared Sounder } \\
\text { (AIRS) [23] }\end{array}$ & $\begin{array}{l}650-2665 \mathrm{~cm}^{-1} \\
\text { ( } 3 \text { non-contiguous } \\
\text { bands) }\end{array}$ & $\begin{array}{l}0.4-2.1 \mathrm{~cm}^{-1} \\
\text { varying with band }\end{array}$ & 13.5 & May 2002-present \\
\hline $\begin{array}{l}\text { Infrared Atmospheric Sounding } \\
\text { Instrument (IASI) [24] }\end{array}$ & $\begin{array}{l}645-2760 \mathrm{~cm}^{-1} \\
\quad(3 \text { contiguous bands })\end{array}$ & $0.5 \mathrm{~cm}^{-1}$ & 12 & $\begin{array}{l}\text { June 2007-present } \\
\text { (MetOp-A) } \\
\text { September 2012-present } \\
\text { (MetOp-B) }\end{array}$ \\
\hline $\begin{array}{l}\text { Cross-track Infrared Sounder } \\
\text { (CrIS) [25] }\end{array}$ & $\begin{array}{l}650-2550 \mathrm{~cm}^{-1} \\
\text { (3 non-contiguous } \\
\text { bands) }\end{array}$ & $\begin{array}{l}0.625-2.5 \mathrm{~cm}^{-1}, \\
\quad \text { varying with band } \\
\text { and operational mode }\end{array}$ & 14 & October 2011-present \\
\hline
\end{tabular}

All nominally have global coverage although note that spectra actually available from the GDR-SI instruments are very limited in both spatial and temporal coverage [26]

Working with other experts, they brought these ideas together, to propose a climate observing system capable of providing benchmark observations for rigorously testing climate model output $[44,45]$. Their vision was to establish a system that gave global coverage, measuring quantities that had the information content required to enable scientists to reduce the uncertainty which existed (and still exists) in projections of future climate, with a demonstrable absolute accuracy and precision that would mean that the measurements could be trusted in perpetuity [46, 47]. Their proposed solution involved the space-based measurement of spectrally resolved thermal infrared radiation and atmospheric refractivity, the latter employing satellites within the Global Positioning System (GPS) network.

Inspired by this work, UK researchers were also questioning how observations of the OLR spectrum could be applied to the problem of climatic change. Slingo and Webb used output from the Hadley Centre climate model to simulate the expected clear-sky changes in spectral OLR between 1860 and 2040 in order to examine the signature of climatic response to greenhouse gas forcing [48]. One of their key findings was the very small changes seen in regions sensitive to mid and upper tropospheric water vapour. These arose because of the propensity of the model to conserve tropospheric relative humidity with time, a signature of positive water vapour feedback. In conjunction, a series of papers by Harries and co-workers investigated the potential of developing spatio-spectral detection fingerprints based on the availability of multi-decadal records from narrow-band radiometers, utilising the simulation results to test their approach [49-51]. The papers highlighted the difficulty of constructing consistent, long-term time series from the operational records and the need to better characterise natural variability in order to assess the significance of any model-observation discrepancy.

Whilst model simulations provided an indication of the expected change in spectrally resolved OLR, the absence of a suitable multi-year observational record with which to confront these simulations was a barrier to progress. This situation would change in the early 2000 s, but prior to this, the few missions designed to measure the OLR spectrum tended, like IRIS-D, to operate for short periods of time (Fig. 1b). Nonetheless, recognising that over a multi-decadal time gap certain forcing signatures should be imprinted in the OLR spectrum, Harries et al. conducted a comparison of clear-sky observations from IRIS-D with those taken almost 30 years later from the Interferometric Monitor for Greenhouse Gases (IMG) [52]. Their findings, re-plotted here in Fig. 3, provided the first observational evidence of the impact of increases in well-mixed greenhouse gases on the OLR spectrum. Subsequent analyses of the temporal and spatial sampling characteristics of the IRIS-D and IMG datasets [53] and of the expected inter-annual variability in the radiation spectrum [54] confirmed that these records alone could not be expected 
Fig. 2 a Global, annual average spectrally resolved OLR as simulated by MODTRAN5 using CCSM3 output for selected years during the twenty-first century under the SRES A2 scenario. b Change in OLR relative to year 2000. Regions of influence of key greenhouse gases are indicated
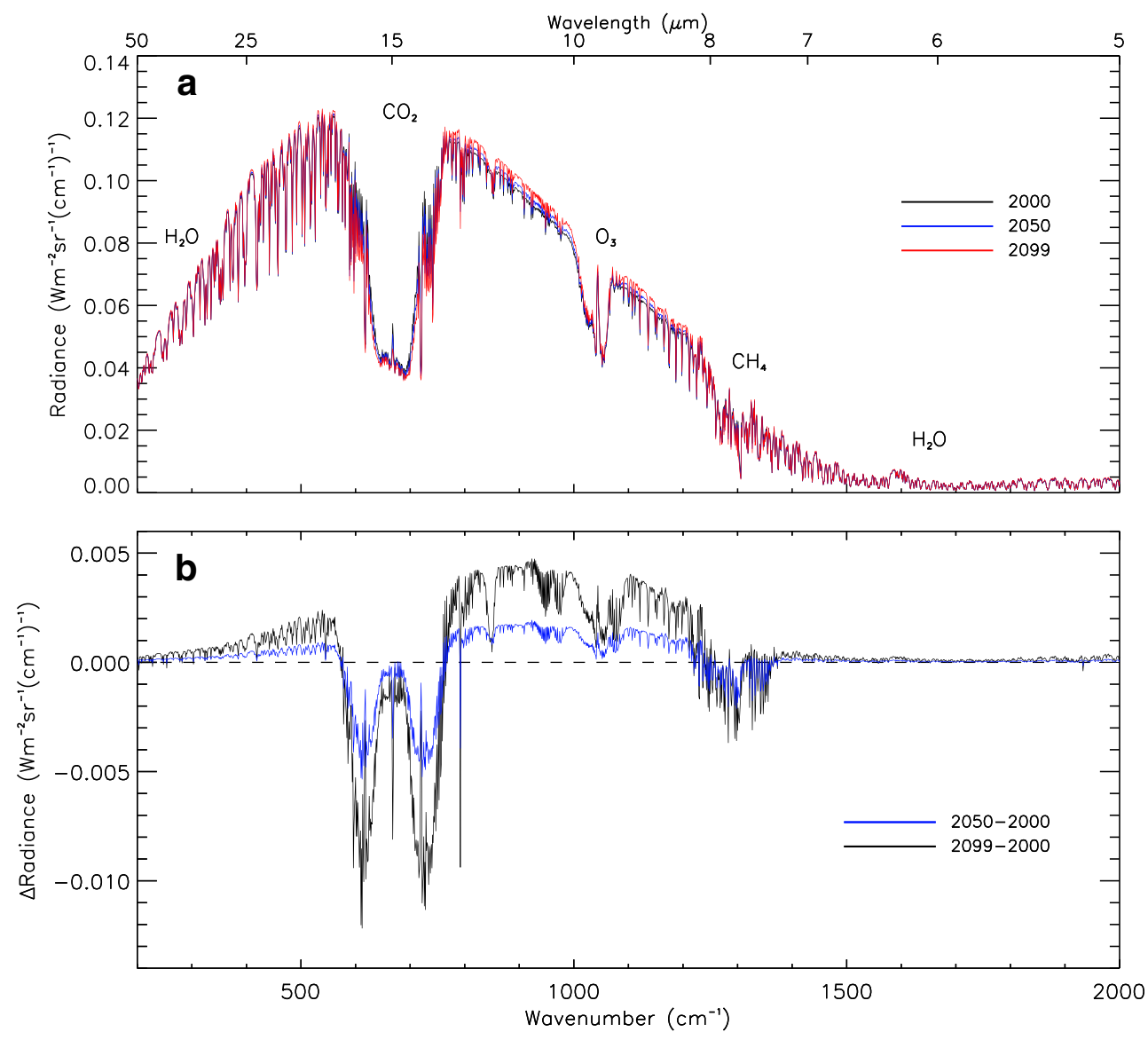

to yield insight into the response of the climate system to the forcing due primarily to their short duration and the sampling of IMG in particular.

\section{Recent Developments: 2000-Present}

Since early 2000, significant progress has been made in our ability to monitor changes in spectral OLR and use this information to test climate models. The launch of AIRS aboard the Aqua satellite in 2002, and the subsequent longevity of the instrument, has meant that researchers have finally had the opportunity to test the evolution of the OLR spectrum as simulated by climate models against sustained hyperspectral measurements. In concert, rigorous approaches have been developed to identify the spectral fingerprints of change and evaluate the timescales on which these will emerge given confounding factors such as natural variability and instrument calibration uncertainty [55]. These efforts have led to initiatives to develop a new category of 'climate change' satellite missions. Principal amongst these is the Climate Absolute Radiance and Refractory Observatory (CLARREO). Selected as a Tier-1 NASA Decadal Survey mission in 2007 [56], CLARREO objectives include the provision of in-orbit absolutely calibrated spectral radiances, spanning the longwave and shortwave domains, in concert with GPS radio occultation measurements.

\section{Insights from AIRS}

Huang and Yung were perhaps the first to use AIRS observations to directly evaluate the variability of the OLR spectrum [57]. They used Empirical Orthogonal Function (EOF) analysis of the AIRS observations to investigate the modes of spectral variability in different climate zones. Although employing only 1 month of data, the authors showed that on this timescale whilst the contrast between cloud top and surface temperature was the dominant factor in driving variability, the patterns and ordering of the modes varied with zone.

The publication was the first in a series using AIRS to evaluate the performance of variants of the Geophysical Fluid Dynamics Laboratory general circulation model (GFDL). Huang et al. performed a detailed comparison of a year of AIRS observations with simulated global mean radiance spectra over the global oceans [58]. The comparison was able to diagnose biases in the model temperature and moisture fields and, more critically, demonstrate that the effects of these biases could compensate such that they would not be apparent 

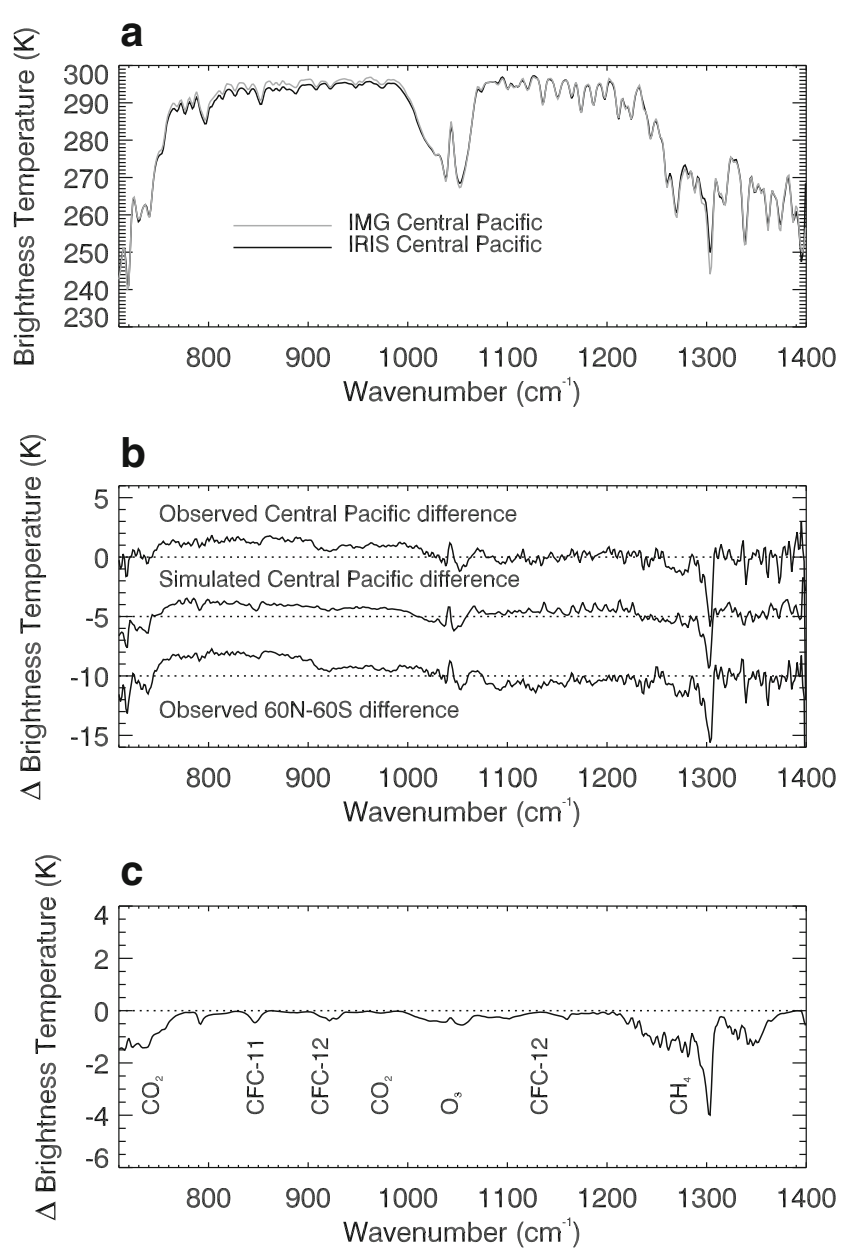

Fig. 3 Examples of IRIS and IMG observed and simulated spectra for a 3-month average (April-June) over selected regions. a Observed IRIS and IMG clear-sky brightness temperature spectra for the central Pacific $\left(10^{\circ} \mathrm{N}-10^{\circ} \mathrm{S}, 130^{\circ} \mathrm{W}-180^{\circ} \mathrm{W}\right)$. b Top, observed difference spectrum taken from (a); middle, simulated central Pacific difference spectrum, displaced by $-5 \mathrm{~K}$; bottom, observed difference spectrum for 'nearglobal' case $\left(60^{\circ} \mathrm{N}-60^{\circ} \mathrm{S}\right)$, displaced by $-10 \mathrm{~K}$. c component of simulated spectrum due to trace gas changes only. 'Brightness temperature' is the equivalent blackbody temperature. (Taken from Harries et al. [52])

in a comparison with broadband flux observations. Comparisons by Huang et al. between GFDL simulations over the tropical oceans and clear-sky spectrally resolved flux spectra derived from AIRS and the Clouds and the Earth's Radiant Energy System (CERES) broadband radiometer yielded similar findings [59] (Fig. 4). The studies also showed that incorporating extra dimensions beyond the spectral to the observation-model comparison added significant discriminatory power. For example, temporal-spatial behaviour was exploited to identify day-night model-observation biases consistent with an incorrect phasing of model convection over the Indian Ocean and Indonesian warm pool [58]. Similarly, Huang et al. were able to suggest a dynamical cause for the discrepancies seen in the water vapour absorption bands by spatially and seasonally decomposing their results [59].
Comparisons of model-observed spectral cloud-radiative forcing by the same authors illustrated marked discrepancies within specific cloud regimes that were not seen when results were averaged over larger spatial domains [60].

Focusing more on factors related to climate sensitivity, Huang and Ramaswamy investigated the spectral variation in the super greenhouse effect (SGE) as manifested in AIRS and GFDL [61]. The SGE phenomenon, essentially a strong anti-correlation between sea surface temperature (SST) and OLR within the tropics, has a strong regional pattern, tending to occur as zones transition between ascent and descent due to the seasonal shift of the Hadley circulation [62]. Analysis of observed and modelled OLR spectra in SGE regions demonstrated the ability to identify compensating errors not only in the mean model spectrum but also in the responses of cloud and the water vapour vertical distribution to a changing SST.

\section{Feedbacks}

The AIRS studies indicated the power of using spectral observations to directly test climate model performance, but techniques to formally discriminate between different feedbacks and unambiguously detect change using radiance spectra needed development. Recognising this, Leroy et al. derived feedback signals due to temperature and water vapour changes realised by an ensemble of the World Climate Research Programme's Coupled Model Intercomparison Project phase 3 (CMIP3) climate models under a particular emissions scenario [63]. They showed an optimal detection technique, incorporating uncertainty in the spectral shape of the feedback signals, could be used to distinguish different signals. They also noted the dominant role of inter-annual variability in determining the accuracy with which a particular feedback could be identified given a 20-year record length.

Although this study provided a framework, the calculations were limited to clear-sky conditions. Using a doubled $\mathrm{CO}_{2}$ climate model simulation, Huang et al. extended the work to separate feedbacks due to temperature, water vapour and, crucially, cloud, in different vertical layers [16]. Key findings related to the similarity between certain feedback signals (Fig. 5) and the impact of uncertainties in the spectral shape of a given fingerprint. Whilst tropospheric temperature and water vapour feedbacks were unambiguously detected for the particular model and forcing scenario considered, distinguishing between cloud and surface temperature feedback signals was difficult. The authors used their results to make the case for auxiliary observations that could help resolve the ambiguity. They highlighted the potential of shortwave spectral reflectance to separate low cloud from surface temperature response and the use of GPS radio occultation measurements to disentangle atmospheric temperature and humidity responses, innovations promised by the CLARREO mission. 

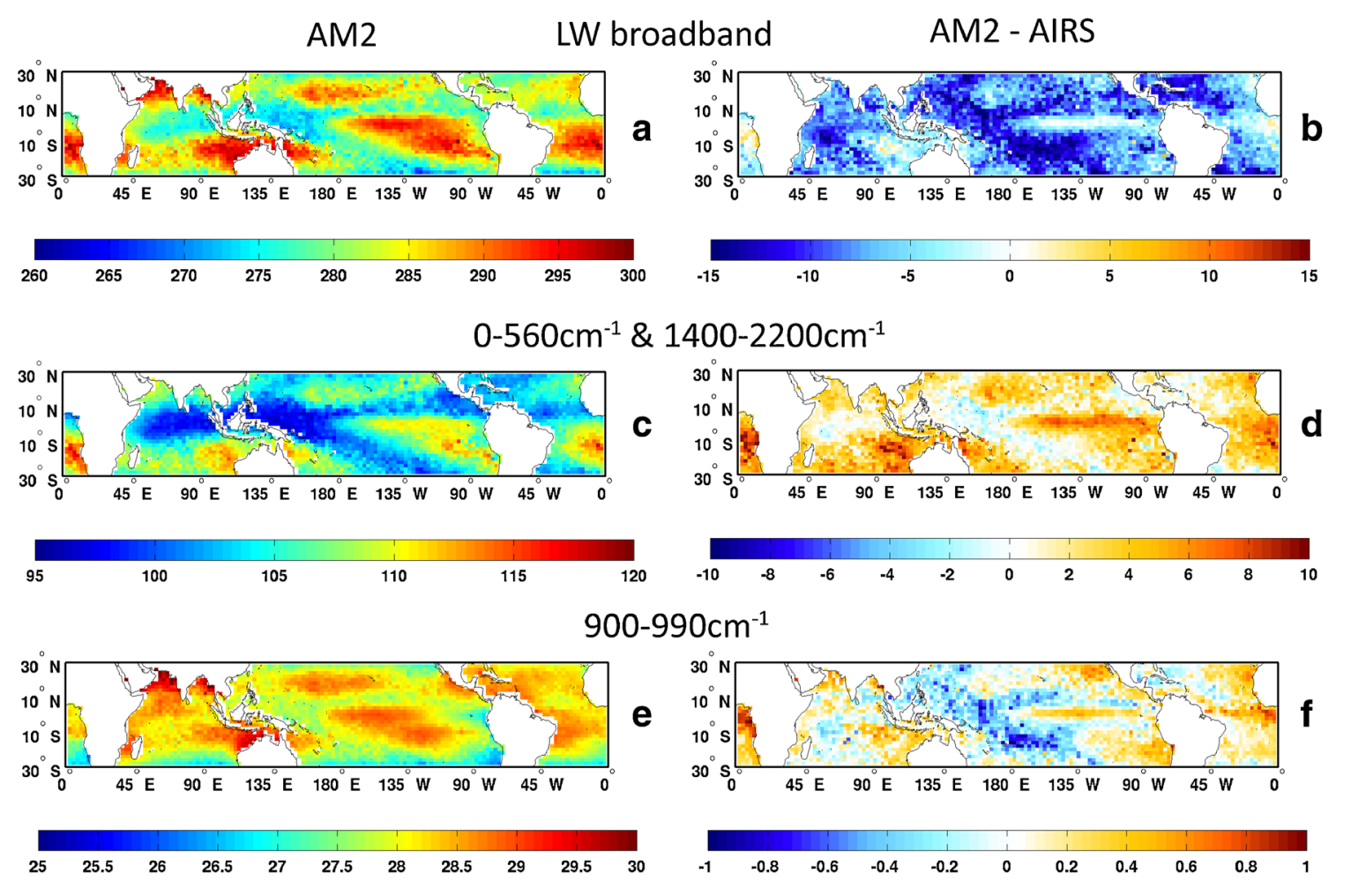

$990-1070 \mathrm{~cm}^{-1}$

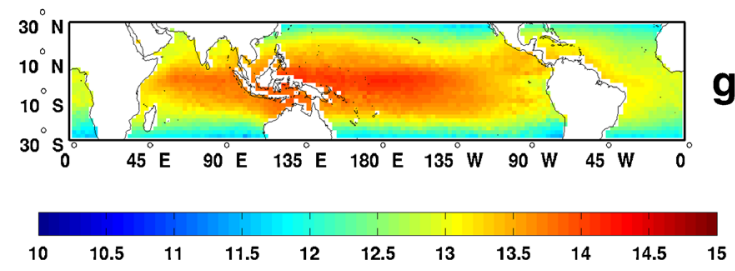

Fig. 4 a Annual mean broadband clear-sky OLR (in $\mathrm{W} \mathrm{m}^{-2}$ ) over the tropical oceans simulated by AM2 (Atmospheric GCM, GFDL) for 2004. b Difference between the AM2-simulated and AIRS inferred broadband clear-sky OLR. c, d As (a) and (b) but for the spectral flux over the combined bands of 0-560 and 1400-2200 $\mathrm{cm}^{-1}$. e-h As (c) and (d) but

\section{Unlocking Information from the RSW Spectrum}

The previous sections highlight the relatively large body of work concerned with discerning climate forcing and feedback processes directly from OLR spectral radiances. Analogous efforts utilising the shortwave spectrum are less well-developed. However, the realisation that the two regions contain complementary information regarding key feedback processes, particularly those involving cloud, coupled with the availability of hyperspectral observations of RSW, has motivated a number of recent studies. Roberts et al. used reflected spectral radiances from the Scanning Imaging Absorption Spectrometer for Atmospheric Cartography (SCIAMACHY) to quantify and attribute the variability in the hyperspectral observations covering the ultraviolet $(0.3 \mu \mathrm{m})$ through to the near infrared $(1.75 \mu \mathrm{m})$ [64]. Employing principal component analysis (PCA) techniques similar to those employed in OLR

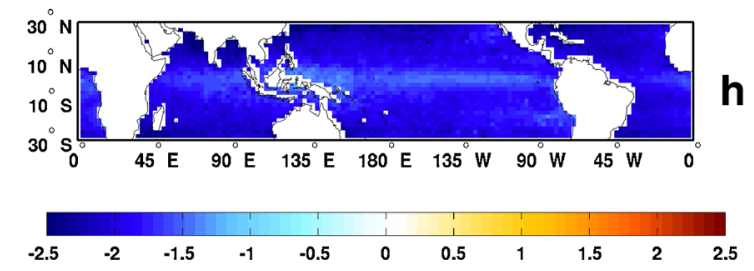

for the spectral ranges of 560-800 and $990-1070 \mathrm{~cm}^{-1}$, respectively. Note the changing scales associated with each panel. Both the sign and spatial distribution of the simulated versus observed differences in the spectrally integrated OLR can change when compared with equivalent differences in selected spectral bands. (Adapted from Huang et al. [59])

studies, they showed that for all of the cases studied, six components or fewer explain over $95 \%$ of the variance in the SCIAMACHY spectra. Perhaps more interestingly, they were able to relate specific PCs to variations in cloud, water vapour, vegetation and sea ice. An alternative approach to characterise variability was proposed by Jin et al. who derived spectral radiative kernels to explore the sensitivity of the RSW spectrum to perturbations of individual parameters such as water vapour, aerosol optical depth and cloud properties. They found, at low-mid latitudes, interannual variability in the RSW spectrum was generally dominated by variability in cloud amount and optical depth [65]. At higher latitudes, snow and sea ice played a more important role. Whilst these effects dominate at wavelengths below $\sim 1.3 \mu \mathrm{m}$, the impact of water vapour and cloud height variability is manifested within the strong water vapour absorption bands across the RSW spectrum. 

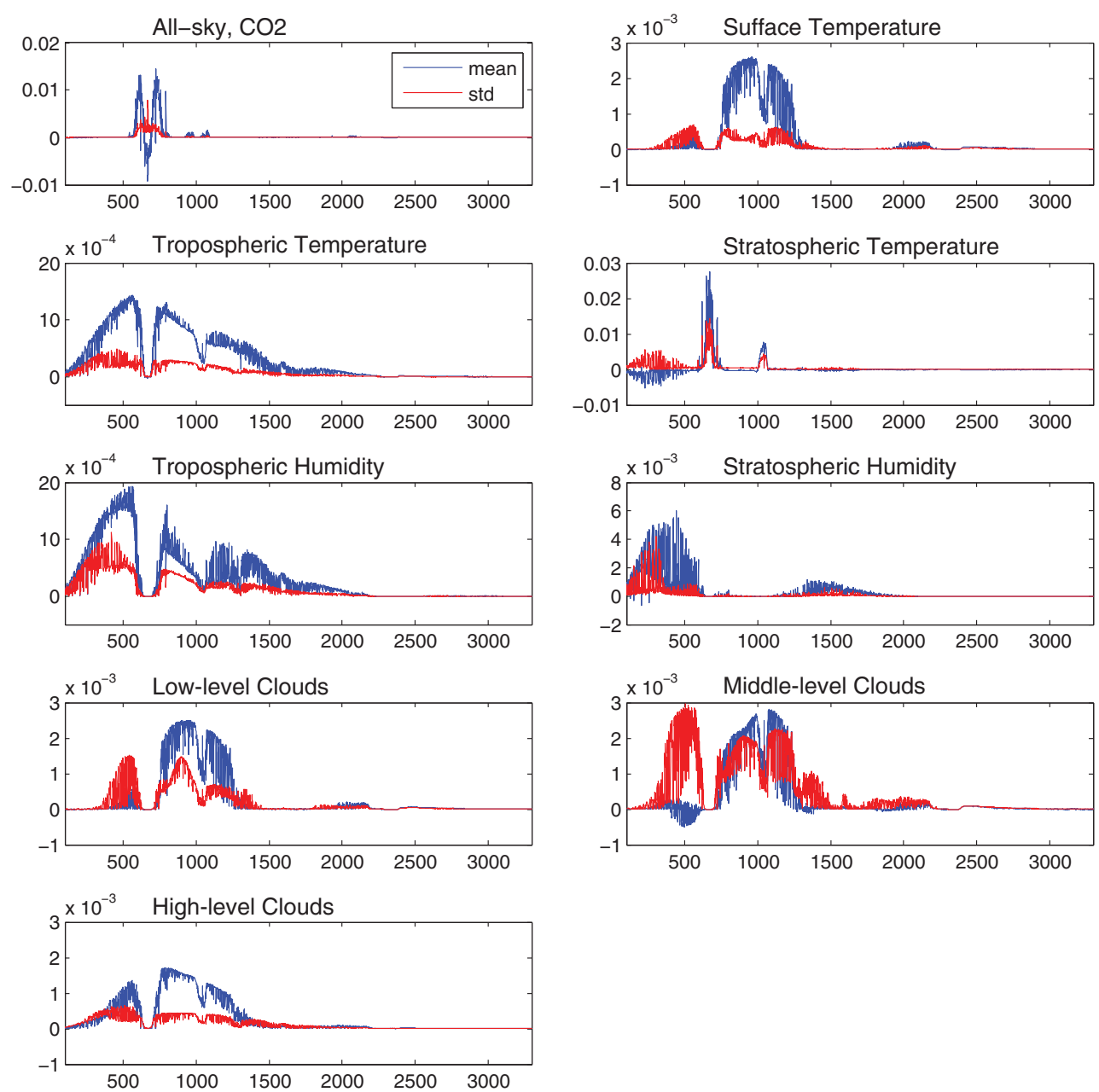

Fig. 5 Examples of the spectral signatures associated with different climate parameter perturbations as realised in a double $\mathrm{CO}_{2}$ experiment using the Canadian Centre for Climate Model Analysis model. Blue curves show the all-sky global mean normalised spectral radiance change $\left(\delta \mathrm{R}^{\mathrm{N}}\right)$ due to the change seen in $\mathrm{CO}_{2}$, surface temperature, tropospheric temperature, stratospheric temperature, tropospheric humidity, stratospheric humidity and lower, middle and upper

Focusing more on longer-term signals of change that might be expected to emerge in the RSW spectrum as the Earth's climate evolves, Feldman et al. pioneered the idea of applying techniques usually employed in the planning of missions or Observing System Simulation Experiments (OSSEs), to climate model output [17]. Coupling CMIP3 simulation results from Community Climate System Model 3 (CCSM3) with radiative transfer modelling across the shortwave domain and applying statistical detection techniques, Feldman et al. were able to determine, as a function of wavelength and zonal band, when the reflectance trend associated with a particular climate model simulation would emerge from the underlying 'natural' variability, or the 'time-to-change-detection' [66]. Focusing on simulations employing the Special Report on Emissions Scenarios (SRES) A2 emission scenario [67], they found that across much of the spectrum, for both clear and all- tropospheric cloud. Red curves represent the spatial standard deviation in the $\delta R^{N}$ values across the globe and can be interpreted as a measure of the 'noise' in the change signal. Strong similarities in the spectral shape of $\delta \mathrm{R}^{\mathrm{N}}$ can clearly be seen in the temperature and low cloud panels (blue curves) indicating the difficulty associated with separating these responses from each other. (Taken from Huang et al. [16])

sky conditions, trends tended to emerge earlier in spectrally resolved reflectances than in broadband albedo (Fig. 6). Typically, signals were faster to emerge at low-mid latitudes compared to higher latitudes, with underlying variability due to cloud accounting for an increase in detection time between the clear and all-sky cases.

\section{Bringing It Together: a Pan-Spectral Approach and the Question of Natural Variability}

Following up on their initial OSSE work, Feldman et al. exploited CMIP3 runs of CCSM3 at a variety of spatial resolutions to investigate whether pan-spectral information, incorporating both the RSW and longwave regimes, could discriminate between models exhibiting different climate sensitivities [68]. In the context of 

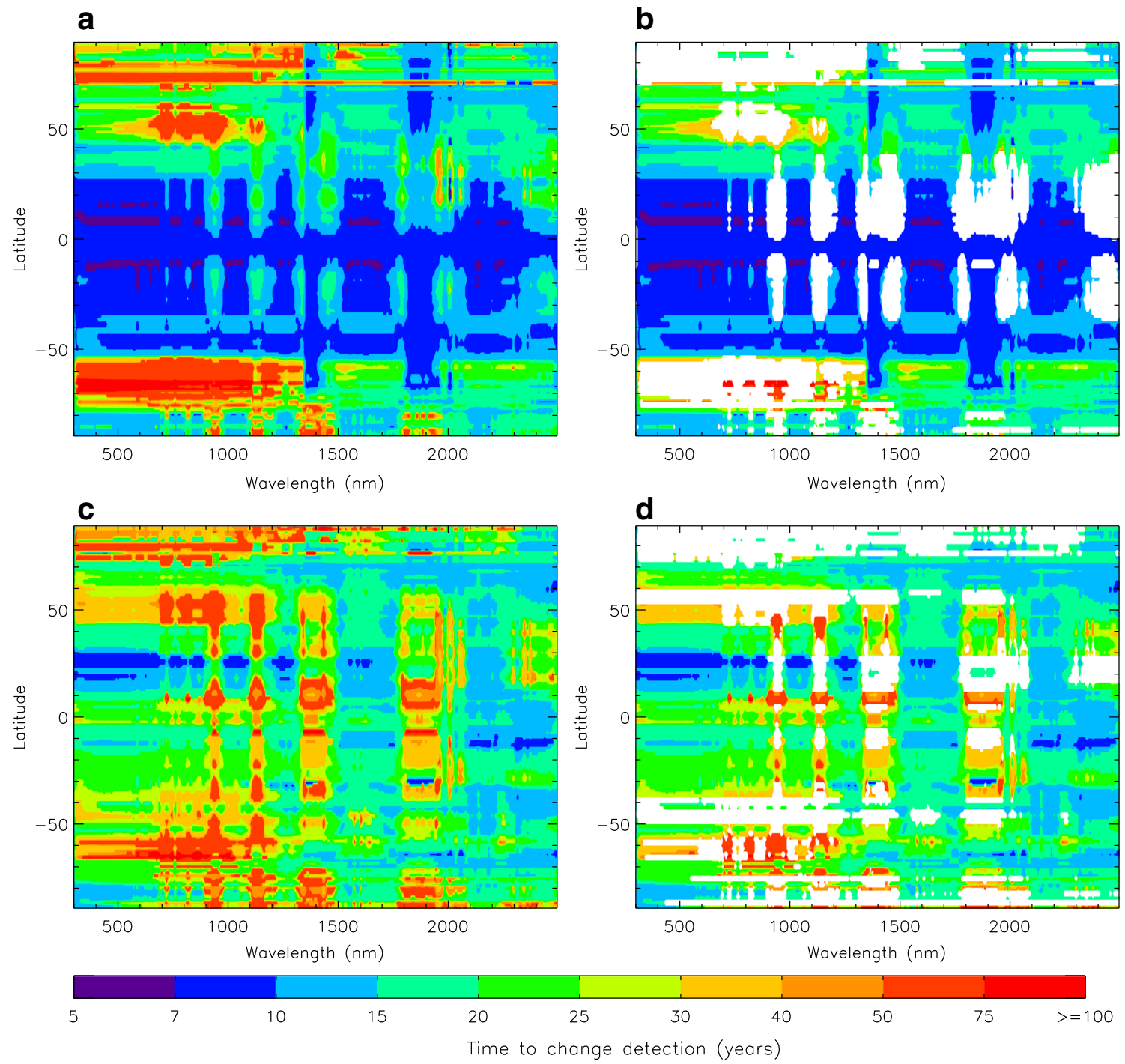

Fig. 6 a Time when the reflectance trend emerges from the underlying 'natural' variability ('time-to-change-detection') as a function of wavelength and zonal band as realised in MODTRAN5 simulations of twenty-first century nadir clear-sky reflectance using output from the CCSM3 model under the SRES A2 scenario. b As (a) but white

regions show where detection times are the same or faster using spectrally integrated broadband albedo. c As (a) for all-sky conditions. d As (b) for all-sky conditions. The approach used to derive each panel follows that described in Feldman et al. [66]

the study goal, to distinguish between models showing different low cloud and sea ice feedback strengths, the RSW domain was shown to have greater sensitivity although the longwave window region between 8 and $12 \mu \mathrm{m}$ also showed promising discriminatory ability. More recent work using output from the HadGEM2-ES and MIROC5 models to simulate multi-decadal spectral trends for a given climate change scenario reiterates the potential of pan-spectral information [27•]. Differences between the two models are apparent in both the RSW and longwave spectral domains (Fig. 7). To fully exploit the spectral dimension requires an understanding of the processes which affect the response at different wavelengths (by, for example, constructing pan-spectral radiative kernels). However, using information contained in both the solar and outgoing longwave regimes simultaneously has the potential to enable feedback processes that appear degenerate when considering either regime in isolation $[16,65]$ to be distinguished from one another.

Clearly, a model needs to accurately capture natural variability to reliably inform on when a climate change signal might be detectable. In the RSW domain, attempts have been made to compare the variability diagnosed from SCIAMACHY with that captured by the CCSM3 OSSE simulations. Roberts et al. used a PCA approach to show that, for selected observation rich months, the two data sets share a large fraction of their spectral variability. This suggests that the OSSE is adequately capturing the spectral variability of the early twenty-first century as observed by SCIAMACHY [69]. 
Fig. 7 Pan-spectral all-sky decadal trends in shortwave reflectance and longwave radiance for the HadGEM2-ES and MIROC5 models under the IPCC AR5 RCP8.5 scenario over the period 2005-2035 averaged over the Arctic $\left(70-90^{\circ} \mathrm{N}\right.$, $\left.0-100^{\circ} \mathrm{E}\right)($ top $)$ and the tropical western Pacific $\left(10^{\circ} \mathrm{S}-10^{\circ} \mathrm{N}\right.$, $\left.100-150^{\circ} \mathrm{E}\right)($ bottom). (Taken from Feldman et al. [27•])

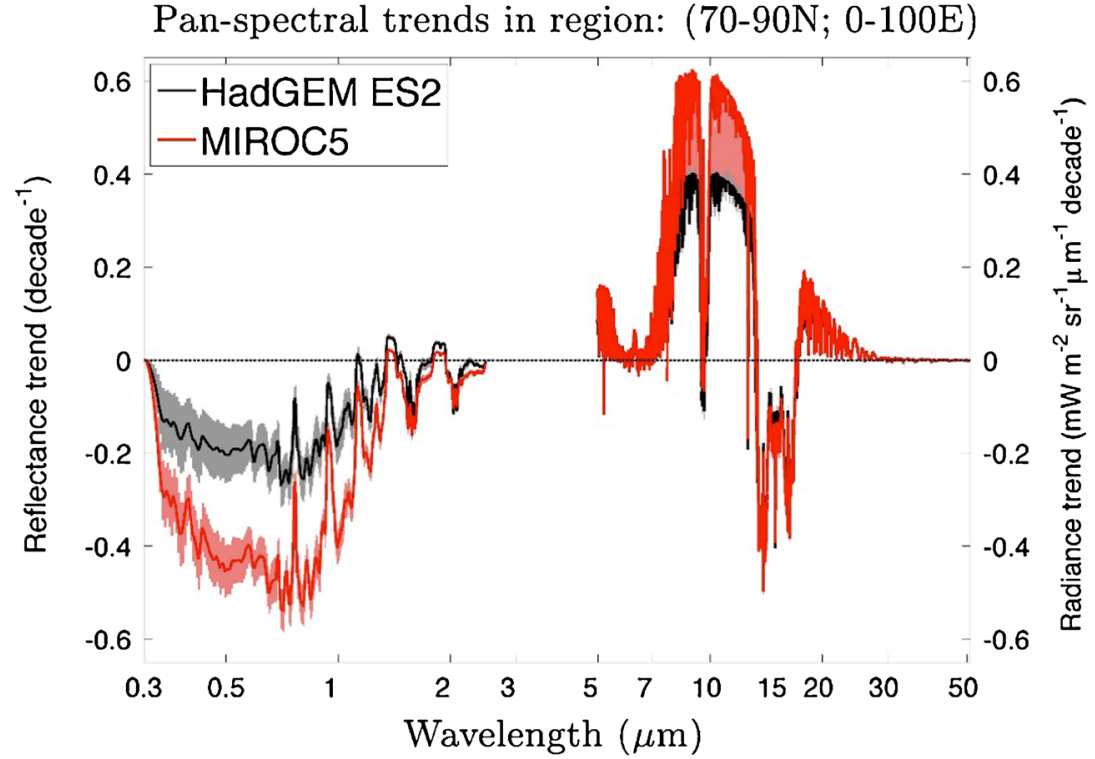

Pan-spectral trends in region: (10S-10N; 100-150E)

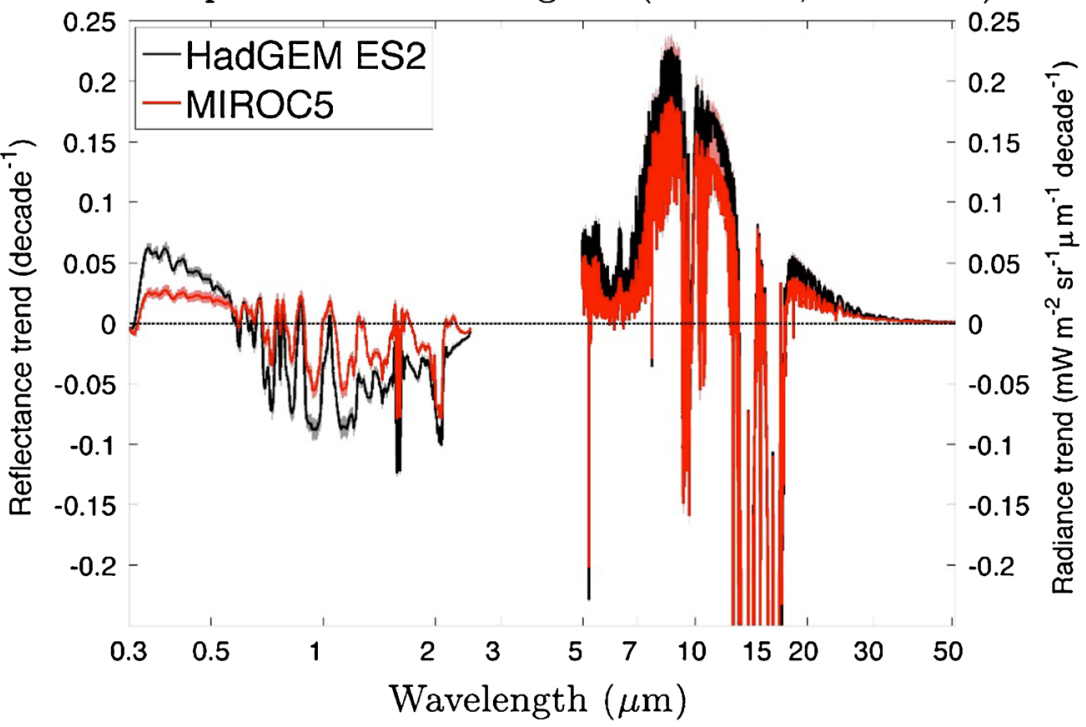

Jin et al., focusing on interannual variability over relatively large spatial domains, showed the normalised OSSE and SCIAMACHY reflectance variabilities are both typically less than $1 \%$ across the RSW spectrum for all regions considered. Their work also highlighted a reduction in inter-annual variability as spatial and temporal averaging scale increases, with a reduction of $\sim 50 \%$ when moving from monthly to annual averages [70•].

Similar work assessing the variability manifested in the OSSE simulations in the longwave regime has not yet been formally reported. However, there are studies providing insight into short-term variability using observations from AIRS and more recently from the Infrared Atmospheric Sounding Interferometer (IASI). Using IASI data, Brindley et al. found interannual variability reduces across the longwave spectrum as spatial scale increases but the rate of reduction varies with spectral region [71•]. As scale increases, variability across the atmospheric window, most sensitive to surface temperature and cloud, reduces relatively rapidly, but the reduction in variability is smaller for spectral regions sensitive to mid-upper troposphere temperature and water vapour (Fig. 8). At the global scale, interannual variability across the entire spectrum is less than $0.17 \mathrm{~mW} \mathrm{~m}^{-2} \mathrm{~cm} \mathrm{sr}^{-1}$, reducing to $0.05 \mathrm{~mW} \mathrm{~m}^{-2} \mathrm{~cm} \mathrm{sr}^{-1}$ in the window. A similar magnitude of spectral interannual variability had previously been reported from an analysis of AIRS data, but the spectral shape of the variability was markedly different [72]. The quality of recent radiance inter-comparisons made between AIRS, IASI and the Cross-Track Infrared Sounder (CrIS) suggests that this difference is most likely due to the different periods considered by 

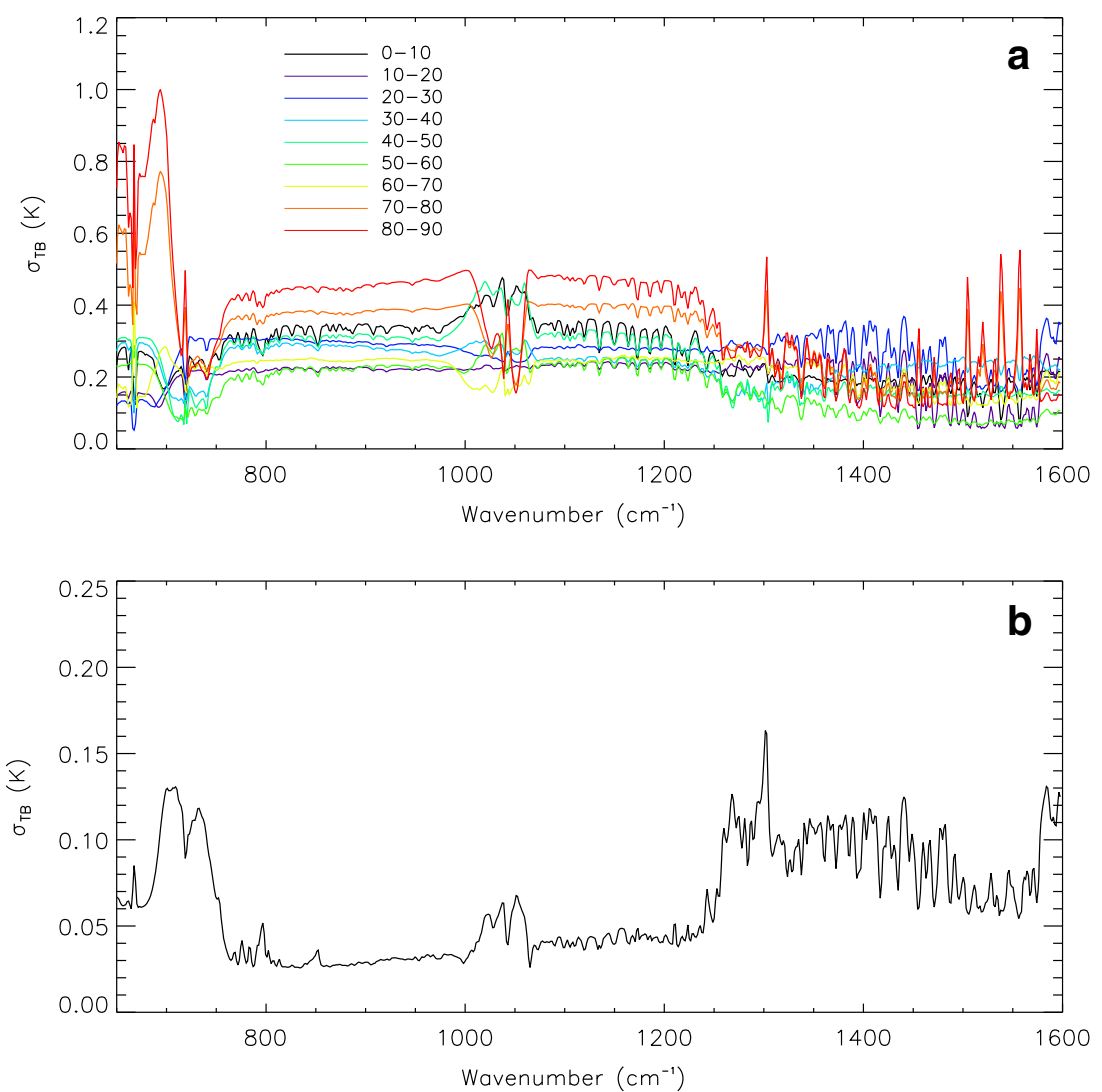

Fig. 8 a Standard deviation in $10^{\circ}$ zonal, annual mean all-sky brightness temperature spectra derived from IASI for the northern hemisphere for the period 2008-2012. b As (a) but for the global mean spectra. Note the change in scale between (a) and (b). Variability in the atmospheric window $\left(\sim 800-1250 \mathrm{~cm}^{-1}\right.$, excluding the ozone band centred at $1040 \mathrm{~cm}^{-1}$ ) reduces more rapidly with spatial scale than in the

the two analyses [73]. However, it would be interesting to carry out a similar study over a common period to confirm that this is indeed the case.

\section{Conclusions and Future Directions}

The work highlighted in this review article illustrates the progress that has been made in measuring and interpreting the outgoing energy spectrum of the Earth across both the shortwave and longwave domains over the last five decades. A key advance concerns the direct use of spectral observations to quantitatively evaluate climate models. These comparisons have identified inadequacies in climate model representations of processes relating to the response of cloud, water vapour and temperature that could not be diagnosed from broadband, spectrally integrated measurements because of compensating effects across the spectrum. As such, they provide an illustration of why such measurements could prove invaluable in reducing the uncertainty range that is currently associated with projections of future climate change [74]. wavelength region between 700 and $750 \mathrm{~cm}^{-1}$ (sensitive on these time scales to variations in upper tropospheric temperature) and at wavenumbers greater than $1250 \mathrm{~cm}^{-1}$ (sensitive to variations in mid-upper tropospheric temperature and water vapour). (Adapted from Brindley et al. [71•])

Considering our future climate, this article has highlighted that whilst the potential of directly using spectrally resolved measurements to diagnose and attribute changes in climate forcing and feedbacks has been recognised for over 40 years, it is only relatively recently that hyperspectral measurements have been of sufficient quality and duration to begin to quantify the observed variability in the reflected shortwave and outgoing longwave spectrum over annual timescales and longer. Such assessments are crucial, as they provide insight into when specific signatures associated with, for example, expected changes in greenhouse gases, aerosol or cloud might be expected to emerge from this 'natural' variability. Moreover, with careful consideration of instrument sampling characteristics, these data can be used to evaluate whether our current generation of current climate and earth system models are able to capture the observed spectral variability. It should be noted that the effort required to transform climate model output such that it can be directly compared with the observed metrics (radiance, reflectance, etc.) is not trivial [27•]. Nonetheless, similar 'satellite simulators' have already been developed for active and narrow-band passive instruments [75] and have 
been used to investigate the ability of a variety of different climate models to correctly capture the seasonality associated with different cloud regimes [76] and to diagnose the reasons for specific common climate model biases [77]. We advocate that developing this capability further for hyperspectral observations should be a high priority. Such an effort would be particularly timely given current and planned future instrumentation (e.g. AIRS, IASI, CrIS, IASI-NG [78]) and could potentially incorporate developments in our ability to perform fast, accurate, high spectral resolution radiative transfer calculations [79] whilst retaining consistency with assumptions made internally within the relevant models [80].

Aligned with the need for the development of suitable tools to directly exploit the information contained in pan-spectral observations, there must also be recognition that, whilst the current generations of hyperspectral instruments are providing observations of unprecedented quality, they were not designed specifically for climate change monitoring. Indeed, we would contend that there is currently no hyperspectral instrument in space that possesses the level of in-orbit, SI traceable calibration or sampling characteristics needed to provide a benchmark record of the true climate state. Efforts are ongoing to rectify this situation via, for example, the CLARREO [81 ••] and Traceable Radiometry Underpinning Solar and Terrestrial Studies (TRUTHS) initiatives [82]. A CLARREO Pathfinder mission is scheduled for launch in 2020 on-board the International Space Station with the goal to demonstrate the target in-orbit calibration accuracy across the RSW domain, and efforts continue to secure funding for the full mission (currently scheduled for launch no earlier than 2023). Implementation of missions with such benchmarking capability is key to understanding discrepancies between contemporaneous measurements from different instruments and, more critically, to being able to make robust claims concerning real spectral changes that have occurred between observing periods when the instrumental record is not continuous in time [83].

Finally, we would also note what we consider to be a major missing piece in our understanding of the response of the Earth's energy budget to climate change. Although in the global mean, approximately half of the Earth's OLR is located at wavelengths greater than $\sim 15 \mu \mathrm{m}$, within the so-called farinfrared (FIR) [84], the region has never been measured spectrally, in its entirety, from space. The FIR is highly sensitive to mid-upper tropospheric water vapour and to cirrus cloud, both of which critically influence the Earth's radiative budget and climate sensitivity [74]. Moreover, very recent work has suggested that the FIR may have a more important role than previously recognised in modulating high-latitude climate response and future change $[85,86]$. We suggest that future missions capable of providing spectrally resolved measurements across this region would ensure we can have confidence we are correctly characterising the full OLR spectrum across the complete range of Earth scenes and address a longstanding shortcoming in our observational capabilities.

Acknowledgments The authors would like to acknowledge Daniel Feldman, Yi Huang and Xianglei Huang for kindly supplying data and modified figures for this manuscript. We also acknowledge Jacqueline Russell and Amy Seales who assisted in the manuscript preparation.

Open Access This article is distributed under the terms of the Creative Commons Attribution 4.0 International License (http:// creativecommons.org/licenses/by/4.0/), which permits unrestricted use, distribution, and reproduction in any medium, provided you give appropriate credit to the original author(s) and the source, provide a link to the Creative Commons license, and indicate if changes were made.

\section{References}

Papers of particular interest, published recently, have been highlighted as:

- Of importance

•• Of major importance

1. Smith W, Hickey J, Howell H, Jacobowitz H, Hilleary D, Drummond A. Nimbus-6 earth radiation budget experiment. Appl Opt. 1977;16:306-18. doi:10.1364/AO.16.000306.

2. Jacobowitz H, Tighe R, The Nimbus-7 ERB Experiment Team. The earth radiation budget derived from the NIMBUS 7 ERB experiment. J Geophys Res. 1984;89:4997-5010. doi:10.1029/JD89iD04 p04997.

3. Barkstrom B. The Earth Radiation Budget Experiment (ERBE). Bull Am Meteorol Soc. 1984;65:1170-85. doi:10.1175/15200477(1984)065<1170:TERBE >2.0.CO;2.

4. Wielicki B, Barkstrom B, Harrison E, Lee R, Smith G, Cooper J. Clouds and the earth's radiant energy system (CERES): an earth observing experiment. Bull Am Meteorol Soc. 1996;77:853-68. doi:10.1175/15200477(1996)077<0853:CATERE>2.0.CO;2.

5. Harries J, Hanafin J, Russell J, et al. The Geostationary Earth Radiation Budget project. Bull Amer Meteorol Soc. 2005;86: 945-60. doi:10.1175/BAMS-86-7-945.

6. Kandel R, Voillier M, Raberanto $\mathrm{P}$, et al. The ScaRaB earth radiation budget dataset. Bull Am Meteorol Soc. 1998;79:765-83. doi:10.1175/1520-0477(1998)079<0765:TSERBD>2.0.CO;2.

7. Duvel J, Viollier M, Raberanto P, et al. The ScaRaB-Resurs earth radiation budget dataset and first results. Bull Am Meteorol Soc. 2001;82:1397-408. doi:10.1175/1520-0477(2001)082 $<1397$ :TSRERB $>2.3 . \mathrm{CO} ; 2$.

8. Desbois M, Capderou M, Eymard L, et al. Megha-Tropiques: un satellite hydrométéorologique franco-indien. La Meterologie. 2007;57:19-27.

9. Loeb N, Wielicki B, Doelling D, et al. Toward optimal closure of the Earth's top-of-atmosphere radiation budget. J Clim. 2009;22: 748-66. doi:10.1175/2008JCLI2637.1.

10. Wong T, Wielicki B, Lee R, Smith G, Bush K, Willis J. Reexamination of the observed decadal variability of the earth radiation budget using altitude-corrected ERBE/ERBS nonscanner WFOV data. J Clim. 2006;19:4028-40. doi:10.1175/JCLI3838.1.

11. Hartmann D, Ramanathan V, Berroir A, Hunt G. Earth radiation budget data and climate research. Rev Geophys. 1986;24:439-68. doi:10.1029/RG024i002p00439. 
12. Ramanathan $\mathrm{V}$. The role of Earth radiation budget studies in climate an general circulation research. J Geophys Res. 1987;92:4075-95. doi:10.1029/JD092iD04p04075.

13. Forster P, Gregory J. The climate sensitivity and its components diagnosed from Earth radiation budget data. J Clim. 2006;19:39-52. doi:10.1175/JCLI3611.1.

14. Tett S, Rowlands D, Mineter M, Cartis C. Can top-of-atmosphere radiation measurements constrain climate predictions? Part II: climate sensitivity. J Climate. 2013;26:9367-83. doi:10.1175/JCLI-D12-00596.1.

15. Hansen J, Nazarenko L, Ruedy R, et al. Earth's energy imbalance: confirmation and implications. Science. 2005;308:1431-5. doi:10.1126/science.1110252.

16. Huang Y, LeroyS, Gero P, Dykema J, Anderson J. Separation of longwave climate feedbacks from spectral observations. J Geophys Res. 2010;115. doi:10.1029/2009JD012766.

17. Feldman D, Algieri C, Ong J, Collins W. CLARREO shortwave observing system simulation experiments of the twenty-first century. J Geophys Res. 2011;116. doi:10.1029/2010JD015350.

18. Goody R, Haskins R, Abdou W, Chen L. Detection of climate forcing using emission spectra. Earth Observ Remote Sens. 1996;13:713-27.

19. Hanel R, Conrath B, Kunde V, et al. The Nimbus 4 infrared spectroscopy experiment: 1 . Calibrated thermal emission spectra. J Geophys Res. 1972;77:2629-41. doi:10.1029/JC077i015p02629.

20. Kempe V, Oertel D, Schuster R, Becker-Ross H, Jahn H. Absolute IR-spectra from the measurement of Fourier-spectrometers aboard Meteor 25 and 28. Acta Astronautica. 1980;7:1403-16. doi:10.1016/0094-5765(80)90015-6.

21. Théodore B, Coppens D, Döhler W, Damiano A, Oertel D, Klaes D, Schmetz J, Spänkuch D. A Glimpse into the past: rescuing hyperspectral SI-1 data from Meteor-28 and 29, Proc. EUMETSAT Meteorological Satellite Conference, 2015; 21-25 September, Toulouse, France.

22. IMG Mission Operation and Verification Committee. Interferometric monitor for greenhouse gases. IMG Project Technical Report (ed. Kobayashi, H.) (Central Research Institute of Electric Power Industry (CRIEPI), Komae Research Laboratory, Komae-shi, Tokyo, 1999).

23. Bovensmann H, Burrows J, Buchwitz M, et al. SCIAMACHY: mission objectives and measurement modes. J Atmos Sci. 1999;56:12750. doi:10.1175/1520-0469(1999)056<0127:SMOAMM $>2.0 . C O ; 2$.

24. Aumann H, Chahine M, Gautier C, et al. AIRS/AMSU/HSB on the aqua mission: design, science objectives, data products, and processing systems. IEEE Trans Geosci Remote Sens. 2003;41:253-64. doi:10.1109/TGRS.2002.808356.

25. Simeoni D, Astruc P, Miras D, et al. Design and development of IASI instrument. Proc SPIE. 2004;5543:208-19. doi:10.1117/12.561090.

26. Han Y, Revercomb H, Cromp M, Gu D, Johnson D, Mooney D, Scott D, Strow L, Bingham G, Borg L, Chen Y, DeSlover D, Esplin M, Hagan D, Jin X, Knuteson R, Motteler H, Predina J, Suwinski L, Taylor J, Tobin D, Tremblay D, Wang C, Wang L, Wang L, Zavyalov V. Suomi NPP CrIS measurements, sensor data record algorithm, calibration and validation activities, and record data quality. J Geophys Res, 2013;118, doi:10.1002/2013jd020344.

27. Feldman D, Collins W, Paige J. Pan-spectral observing system simulation experiments of shortwave reflectance and longwave radiance for climate model evaluation. Goesci Model Dev. 2015;8: 1943-54. doi:10.5194/gmd-8-1943-2015. Gives background into how to perform a climate OSSE and shows how pan-spectral information could prove valuable in discriminating between the response of different climate models to a given forcing scenario.

28. Molnar G, Susskind J. Atmospheric parameter climatologies from AIRS: monitoring short- and longer term climate variabilities and "trends". Proc. SPIE, 2008;6966. doi:10.1117/12.775446.
29. Pagano T, Chahine M, Olsen E. Seven years of observations of midtropospheric $\mathrm{CO}_{2}$ from the Atmospheric Infrared Sounder. Acta Astronautica. 2011;69:355-9. doi:10.1016/j.actaastro.2011.05.016.

30. Gettleman A, Collins W, Fetzer E, et al. Climatology of uppertropospheric relative humidity from the Atmospheric Infrared Sounder and implications for climate. J Clim. 2006;19:6104-21. doi:10.1175/JCLI3956.1.

31. Pan F, Huang X, Strow L, Gou H. Linear trends and closures of 10-yr observations of AIRS stratospheric channels. J Clim. 2015;28:8939-50. doi:10.1175/JCLI-D-15-0418.1.

32. Madden R, Ramanathan V. Detecting climate change due to increasing carbon dioxide. Science. 1980;209:763-8. doi:10.1126/science.209.4458.763.

33. Hansen J, Johnson D, Lacis A, et al. Climate impact of increasing atmospheric carbon dioxide. Science. 1981;213:957-66. doi:10.1126/science.213.4511.957.

34. Kukla G, Gavin J. Summer ice and carbon dioxide. Science. 1981;214:497-503. doi:10.1126/science.214.4520.497.

35. Gornitz V, Lebedeff S, Hansen J. Global sea level trend in the past century. Science. 1982;215:1611-4. doi:10.1126 /science.215.4540.1611.

36. Kiehl J. Satellite detection of effects due to increased atmospheric carbon dioxide. Science. 1983;222:504-6. doi:10.1126/science.222.4623.504.

37. Charlock $\mathrm{T} . \mathrm{CO}_{2}$ induced climatic-change and spectral variations in the outgoing terrestrial infrared radiation. Tellus-B. 1984;36:139-48.

38. Prabhakara C, Dalu G, Kunde V. Search for global and seasonalvariation of methane from Nimbus-4 IRIS measurements. J Geophys Res. 1974;79:1744-9. doi:10.1029/JC079i012p01744.

39. Prabhakara C, Fraser R, Dalu G, Wu M, Curran R, Styles T. Thin cirrus clouds - seasonal distribution over oceans deduced from Nimbus-4 IRIS. J Appl Meteorol. 1988;27:379-99. doi:10.1175 /1520-0450(1988)027<0379:TCCSDO>2.0.CO;2.

40. North G, Kim K-Y, Shen S, Hardin J. Detection of forced climate signals. 1. Filter theory. J Climate. 1995;8:401-8. doi:10.1175 /15200442(1995)008<0401:DOFCSP >2.0.CO;2.

41. Haskins R, Goody R, Chen L. A statistical method for testing a general circulation model with spectrally resolved radiances. J Geophys Res. 1997;102:16563-81. doi:10.1029/97JD00897.

42. Goody R, Haskins R. Calibration of radiances from space. J Clim. 1998;11:754-8. doi:10.1175/1520-0442(1998)011 $<0754$ :CORFS $>2.0 . \mathrm{CO} ; 2$.

43. Huang X, Farrara J, Leroy S, Yung Y, Goody R. Cloud variability as revealed in outgoing infrared spectra: comparing model to observations with spectral EOF analysis. Geophys Res Lett. 2002;29:1270. doi:10.1029/2001GL014176.

44. Keith D, Anderson J. Accurate spectrally resolved infrared radiance observation from space: implications for the detection of decade-tocentury-scale climatic change. J Clim. 2001;14:979-90. doi:10.1175/1520-0442(2001)014<0979:ASRIRO>2.0.CO;2.

45. Anderson J, Dykema J, Goody R, Hu H, Kirk-Davidoff D. Absolute, spectrally-resolved, thermal radiance: a benchmark for climate monitoring from space. J Quant Spectrosc Radiat Transf. 2004;85:367-83. doi:10.1016/S0022-4073(03)00232-2.

46. Goody R, Anderson J, Karl T, et al. Why monitor the climate? Bull Am Meteorol Soc. 2002;83:873-8. doi:10.1175/1520-0477 (2002)083<0873:WWSMTC $>2.3 . C O ; 2$.

47. Goody R, Anderson J, North G. Testing climate models: an approach. Bull Am Meteorol Soc. 1998;79:2541-9. doi:10.1175/1520-0477(1998)079<2541:TCMAA>2.0.CO;2.

48. Slingo A, Webb M. The spectral signature of global warming. Q J R Meteorol Soc. 1997;123:293-307. doi:10.1256/smsqj.53802.

49. Harries J, Brindley H, Geer A. Climate variability and trends from operational satellite spectral data. Geophys Res Lett. 1998;25: 3975-8. doi:10.1029/1998GL900056. 
50. Brindley H, Geer A, Harries J. Climate variability and trends in SSU radiances: a comparison of model predictions and satellite observations in the middle stratosphere. J Clim. 1999;12:3197219. doi:10.1175/1520-0442(1999)012<3197:CVATIS >2.0.CO;2.

51. Geer A, Harries J, Brindley H. Spatial patterns of climate variability in upper-tropospheric water vapor radiances from satellite data and climate model simulations. J Clim. 1999;12:1940-55. doi:10.1175 /1520-0442(1999)012<1940:SPOCVI>2.0.CO;2.

52. Harries J, Brindley H, Sagoo P, Bantges R. Increases in greenhouse forcing inferred from the outgoing longwave spectra of the Earth in 1970 and 1997. Nature. 2001;410:355-7. doi:10.1038/35066553.

53. Brindley H, Harries J. Observations of the infrared outgoing spectrum of the Earth from space: the effects of temporal and spatial sampling. J Clim. 2003;16:3820-33. doi:10.1175/1520-0442 (2003)016<3820:OOTIOS >2.0.CO;2.

54. Brindley H, Allan R. Simulations of the effects of interannual and decadal variability on the clear-sky outgoing longwave radiation spectrum. Q J R Meteorol Soc. 2003;129:2971-298. doi:10.1256/qj.02.216.

55. Leroy S, Anderson J, Ohring G. Climate signal detection times and constraints on climate benchmark accuracy requirements. J Clim. 2008;21:841-6. doi:10.1175/2007JCL1946.1.

56. NRC. Earth science and applications from space: national imperatives for the next decade and beyond. National Academy Press, 2007, 428 pp.

57. Huang X, Yung Y. Spatial and spectral variability of the outgoing thermal IR spectra from AIRS: a case study of July 2003. J Geophys Res. 2005;110. doi:10.1029/2004JD005530.

58. Huang Y, Ramaswamy V, Huang X, Fu Q, Bardeen C. A strict test in climate modeling with spectrally resolved radiances: GCM simulation versus AIRS observations. Geophys Res Lett, 2007;34. doi:10.1029/2007GL031409.

59. Huang X, Yang W, Loeb N, Ramaswamy V. Spectrally resolved fluxes derived from collocated AIRS and CERES measurements and their application in model evaluation: clear sky over the tropical oceans. J Geophys Res. 2008;113. doi:10.1029/2007JD009219.

60. Huang X, Loeb N, Yang W. Spectrally resolved fluxes derived from collocated AIRS and CERES measurements and their application in model evaluation: 2. Cloudy sky and band-by-band cloud radiative forcing over the tropical oceans. J Geophys Res. 2010;115. doi:10.1029/2010JD013932.

61. Huang Y, Ramaswamy. Observed and simulated seasonal covariations of outgoing longwave radiation spectrum and surface temperature. Geophys Res Lett. 2008;35. doi:10.1029/2008GL034859

62. Bony S, Lau K, Sud Y. Sea surface temperature and large-scale circulation influences on tropical greenhouse effect and cloud radiative forcing. J Clim. 1997;10:2055-77. doi:10.1175/1520-0442 (1997)010<2055:SSTALS $>2.0$. CO;2.

63. Leroy S, Anderson J, Dykema J, Goody R. Testing climate models using thermal infrared spectra. J Clim. 2008;21:1863-75. doi:10.1175/2007JCLI2061.1.

64. Roberts Y, Pilewskie P, Kindel B. Evaluating the observed variability in hyperspectral Earth-reflected solar radiance. J Geophys Res. 2011;116. doi:10.1029/2011JD016448.

65. Jin Z, Wielicki B, Loukachine C, Charlock T, Young D, Noel S. Spectral kernel approach to study radiative response of climate variables and interannual variability of reflected solar spectrum. J Geophys Res. 2011;116. doi: 10.1029/2010JD015228,

66. Feldman D, Algieri C, Collins W, Roberts Y, Pilewskie P. Simulation studies for the detection of changes in broadband albedo and shortwave nadir reflectance spectra under a climate change scenario. J Geophys Res. 2011:116. doi:10.1029/2011JD0160407.

67. Intergovernmental Panel on Climate Change (IPCC). Special report on emissions scenarios: a special report of working group III of the Intergovernmental Panel on Climate Change. In: N. Nakicenovic et al. (eds), 2000; 599pp., Cambridge University Press, Cambridge, UK.
68. Feldman D, Coleman D, Collins W. On the usage of spectral and broadband satellite instrument measurements to differentiate climate models with different cloud feedback strengths. J Clim. 2013;26:6561-74. doi:10.1175/JCLI-D-12-00378.1.

69. Roberts Y, Pilewskie P, Kindel B, Feldman D, Collins W. Quantitative comparison of the variability in observed and simulated shortwave reflectance. Atmos Chem Phys. 2013;13:3133-47. doi:10.5194/acp-13-3133-2013.

70. Jin Z, Lukachin C, Roberts Y, Wielicki B, Feldman D, Collins W. Interannual variability of the Earth's spectral solar reflectance from measurements and simulations. J Geophys Res. 2014;119:4458-70. doi:10.1002/2013JD021056. Shows that the directly observed inter-annual variability across the RSW spectrum is typically very small (less than a few percent) when averaged over large spatial domains (e.g. tropics, mid-latitudes), and that this variability is well captured by radiative transfer simulations informed both by climate model output and geophysical retrievals from other satellite instruments.

71. Brindley H, Bantges R, Russell J, et al. Spectral signatures of Earth's climate variability over 5 years from IASI. J Clim. 2015;28:1649-60. doi:10.1175/JCLI-D-14-00431.1. Quantifies inter-annual variability across the OLR spectrum for a range of spatial scales and shows how both the magnitude and shape of the spectral variability change as spatial scale increases.

72. Huang Y, Ramaswamy V. Evolution and trend of the outgoing longwave radiation spectrum. J Clim. 2009;22:4637-51. doi:10.1175/2009JCLI2874.1.

73. Wang L, Han Y, Jin X, Chen Y, Tremblay D. Radiometric consistency assessment of hyperspectral infrared sounders. Atmos Meas Tech. 2015;8:4831-44. doi:10.5194/amt-8-4831-2015.

74. IPCC. Climate change 2013: the physical science basis. Contribution of Working Group I to the Fifth Assessment Report of the Intergovernmental Panel on Climate Change. T.F. Stocker, D. Qin, G.-K. Plattner, M. Tignor, S.K. Allen, J. Doschung, A. Nauels, Y. Xia, V. Bex, and P.M. Midgley, Eds. Cambridge University Press, 741-882, doi:10.1017/CBO9781107415324.020.

75. Bodas-Salcedo A, Webb M, Bony S, et al. COSP satellite simulation software for model assessment. Bull Am Meteorol Soc. 2011;92:1023-43. doi:10.1175/2011BAMS2856.1.

76. Tsushima Y, Ringer M, Webb M, Williams K. Quantitative evaluation of the seasonal variations in climate model cloud regimes. Clim Dyn. 2013;41:2679-96. doi:10.1007/s00382-012-1609-4.

77. Bodas-Salcedo A, Williams K, Ringer M, et al. Origins of the solar radiation biases over the Southern Ocean in CFMIP2 models. J Clim. 2014;27:41-56. doi:10.1175/JCLID-13-00169.1.

78. Crevoisier C, Clerbaux C, Guidard V, et al. Towards IASI-New Generation (IASI-NG): impact of improved spectral resolution and radiometric noise on the retrieval of thermodynamic, chemistry and climate variables. Atmos Meas Tech. 2014;7:4367-85. doi:10.5194/amt-7-4367-2014.

79. Liu X, Smith W, Zhou D, Larar A. Principal componentbased radiative transfer model for hyperspectral sensors: theoretical concept. Appl Optics. 2006;45:201-9. doi:10.1364 /AO.45.000201.

80. Chen X, Huang X, Liu X. Non-negligible effects of cloud vertical overlapping assumptions on longwave spectral fingerprinting studies. J Geophys Res. 2013;118:7309-20. doi:10.1002/jgrd.50562.

81.• Wielicki B, Young D, Mlynczak M, et al. Achieving climate change accuracy in orbit. Bull Amer Meteorol Soc. 2013;94:1519-39. doi:10.1175/BAMS-D-12-00149.1 Describes the CLARREO mission concept and proposes methods for formally determining accuracy requirements for a wide range of climate variables. 
82. Fox N, Kaiser-Weiss A, Schmutz W, Thome K, Young D, Wielicki B, Winkler R, Woolliams E. Accurate radiometry from space: an essential tool for climate studies. Phil Trans Roy Soc. 2011;369. doi: 10.1098/rsta.2011.024664.

83. Bantges R, Brindley H, Chen X, Huang X, Harries J, Murray J. On the detection of robust multi-decadal changes in the Earth's outgoing longwave radiation spectrum. Accepted for publication in J. Climate. 2016. doi: 10.1175/JCLI-D-15-0713.1.
84. Harries J, Carli B, Rizzi R, Serio C, Mlynczak M, Palchetti L, Maestri T, Brindley H, Masiello G. The far infrared Earth. Rev Geophys. 2008;46. doi: 10.1029/2007RG000233.

85. Feldman D, Collins W, Pincus R, Huang X, Chen X. Far-infrared surface emissivity and climate. Proc Nat Acad Sci Amer. 2014;111: 16297-302. doi:10.1073/pnas.1413640111.

86. Cox C, Walden V, Rowe P, Shupe M. Humidity trends imply increased sensitivity to clouds in a warming Arctic. Nature Comm. 2015;6. doi:10.1038/ncomms10117. 